DOI - https://doi.org/10.5965/2316796309182020126

\title{
MODELO DE AVALIAÇÃO E TRADUÇÃO DA EXPERIÊNCIA COGNITIVAE AFETIVA \\ DE PRODUTO
}

\section{EVALUATION AND TRANSLATION MODEL OF COGNITIVE AND AFFECTIVE PRODUCT EXPERIENCE}

David Ribeiro Tavares ${ }^{1}$

Osíris Canciglieri Jr ${ }^{2}$

Lia Buarque de Macedo Guimarães ${ }^{3}$ Marcelo Rudek 4 


\section{Resumo}

A experiência de interação entre The experience of interaction between consumidor e produto é essencialmente consumer and product is essentially subjetiva e de difícil avaliação e tradução. subjec-tive and difficult to evaluate and Nela, há fatores cognitivos e afetivos que translate. There are cognitive and affective são esti-muladosporatributos deprodutos factors that are stimulated by product incorporadas ao design que podem ser attributes incorporated into the design funcio-nais e hedônicos. O objetivo do that can be functional and hedonic. design cognitivo e afetivo é conquistar The objective of cognitive and affective - consumi-dor com produtos que design is to con-quer the consumer proporcionam experiências inovadoras with products that provide innovative com intenso impacto funcional e experiences with intense functional "cognitivo" como facilidades de uso, além and "cognitive" impact as ease of use do impacto "afetivo" como o prazer de in addition to the "affective" impact as consumir. Contudo, modelos é métodos the pleasure of consuming. However de engenharia e design tem difi-culdades models and methods of engineering and de avaliação e tradução das informações, design have difficulties in evaluating and pois é difícil antecipar a inten-ção e translating information, as it is difficult preferência do consumidor. Osfenômenos to anticipate the consumer's intention ocorrem dentro da mente, cérebro, e and preference. The phenomena occur fazem parte da experiência subjetiva e não within the mind, brain, and are part of the são, portanto, acessíveis ao observa-dor subjective experience and are therefore um modelo de avaliação e tradução da The objective of this article is to propose experiência cognitiva e afetiva de produto, a model for the evaluation and translation por meio de uma abordagem multidisci- of the cognitive and affective experience plinar de paradigma cognitivista. Como of the product, through a multidisciplinary resultado, é proposto três indicadores que approach of cognitive paradigm. As a contribuem para o avanço nos estudos resultibute to the advancement of studies
sobre a subjetividade do consumidor. Palavras-chave: modeloconceitual; design on con-sumer subjectivity.

cognitivo e afetivo; experiência de produto; intencionali-dade.

Key-words: conceptual model; cognitive and affective design; product experience; intentionality.
${ }^{1}$ Mestre - PUC-PR (economicdavid@hotmail.com) 2 Doutor - PUC-PR (osiris.canciglieri@pucpr.br)

${ }^{3}$ Doutora - UFRGS (liabmg@gmail.com)

${ }^{4}$ Doutor - PUC-PR (marcelo.rudek@pucpr.br)
ISSN: 2316-7963

\section{INTRODUÇÃO}

Atualmente, produtos precisam atender a diferentes necessidades e preferências humanas. A tradução e aplicação de fatores cognitivos e afetivos em produtos é um desafio em áreas de pesquisa. A lacuna identificada é que cognição e afeto são fatores humanos subjetivos e, portanto, de difícil tradução por equipes de en-genharia e design de produto. O design de produto é o campo de pesquisa que busca as melhores práticas de concepção e desenvolvimento de produtos e divide, juntamente com a engenharia, o marketing e a psicologia, desafios comuns identificados na relação entre produto e consumidor, o contexto de interação, e a experi-ência entre produto e consumidor. Há uma distância entre a intuição e percepção do design e a do consumidor.

É inevitável abordar os aspectos cognitivos e afetivos no design de produto sem se aprofundar no fenômeno da experiência humana. Dubet (1994) escreve que a noção de experiência é ambígua e vaga, especialmente porque evoca dois fenômenos contraditórios. No primeiro sentido, a experiência é uma forma de sentir, que é invadida por um estado emocional, e assim é usualmente descrita a experi-ência estética, amorosa, etc. Para a experiência emocional, um segundo significado é colocado: a experiência é também uma atividade cognitiva. É uma forma de cons-truir o que é real e, especialmente, verificá-lo, "experimentá-lo", seja no nível afetivo ou emocional, seja no nível cognitivo. Entende-se, portanto, que a experiência é um fenômeno afetivo e cognitivo que envolve o usuário, a marca, o produto, e diferen-tes conceitos utilizados para a experiência na pesquisa sobre o consumidor (Gó-mez-Corona et al., 2017) e sobre o produto (Schifferstein \& Hekker, 2011).

O design cognitivo e afetivo de produto buscam avançar por estas lacunas, propondo um design centrado no humano, suas necessidades e preferências. Jor-dan (1998, 1999, 2000), Desmet (2003) e Norman (1988; 2004) foram pioneiros em abordar com maior profundidade o design cognitivo e afetivo. Também em conside-rar os diferentes níveis existentes entre os fatores cognitivos e afetivos. Cognição e afeto fazem parte de um fluxo de informação subjetiva, e Norman (2004) os descre-veu como sistemas de processamento de informações. O sistema cognitivo dá sen-tido ao mundo enquanto que o sistema afetivo é crítico em relação a ele. Cada sis-tema influencia o outro, com a cognição proporcionando afeto e sendo afetada por ele (Ashby et al., 1999; Coates, 2003; Crilly et al., 2004). O desafio, contudo, está em entender a mecânica e o funcionamento da intelectualidade humana e de suas pre-ferências.

É possível afirmar que cada pessoa tem seus próprios objetivos e as causas das escolhas de consumo (Desmet, 2003; Ellsworth \& Scherer, 2003; Kumar \& Garg, 2010) que podem ser, de maneira geral, tanto pela funcionalidade ou a facili-dade quanto pelo prazer ou a agradabilidade que o produto oferece. Ou ainda, por qualidades oriundas de atributos cognitivos e afetivos oferecidos por um mesmo produto. Quando produtos de diferentes categorias e marcas em diferentes merca-dos levam prazer "afetivo" e funcionalidade "cognitiva" aos consumidores, surgem os questionamentos de que razões levam o consumidor a escolher entre produtos; se há produtos que oferecem uma experiência mais agradável e afetiva do que ou-tros; se há produtos que são mais fáceis e compreensíveis; se é valido afirmar que produtos devem satisfazer tanto as necessidades cognitivas e funcionais quanto as afetivas e de prazer.

Produtos podem ser fáceis de usar e ao mesmo tempo provocar prazer ao consumidor. Para atender a este objetivo, designers necessitam reconhecer as dife- 
renças existentes entre necessidades para a satisfação funcional e necessidades para a satisfação emocional, como afirmam Khalid \& Helander (2004). Contudo, há o problema de avaliar e traduzir opiniões e respostas resultado da experiência cog-nitiva e afetiva de produto que é essencialmente subjetiva. Poucas abordagens buscam explicar a importância de uma aplicação integrada e que envolva todos os processos cognitivos e afetivos do consumidor (Jiao et al., 2017; Khalid \& Helander, 2006; Zhou et al., 2013), devido a complexidade deste "campo minado" (Khalid \& Helander, 2006; Khalid, 2006), ou "caixa preta" (Diego-Mas \& Alcaide-Marzal, 2016; Jiao et al., 2017; Zhou et al., 2013). Esta lacuna se mostra como um dos principais problemas para o design de produto centrado em fatores humanos. Dessa forma, questionamos: é possível avaliar e traduzir da experiência cognitiva e afetiva de produto?

O objetivo deste artigo é propor um modelo conceitual de avaliação e tradu-ção da experiência cognitiva e afetiva de produto. $O$ modelo parte de uma aborda-gem multidisciplinar de paradigma cognitivista, e tem o intuito de contribuir para o avanço dos estudos da complexidade do que ocorre dentro da "caixa preta" da expe-riência cognitiva e afetiva, ou experiência de produto como afirmam Schifferstein \& Hekke (2011).

\section{BACKGROUND}

\subsection{Experiência de produto}

Schifferstein \& Hekker (2011) descreve que a experiência de produto parte dos efeitos psicológicos provocados pela interação, incluindo o grau em que todos os sentidos são estimulados e os significados e valores são atribuídos aos produtos, além dos sentimentos e emoções que são provocados. Para o sucesso de produtos as recompensas emocionais tem importância chave, e criar conexões profundas com consumidores por meio de associações significativas (Orth \& Thurgood, 2018) é valorizado por criar laços com suas crenças, experiências, memórias, pessoas, lugares, ou ainda valores pessoais (Noble \& Kumar, 2008). É estratégico, portanto, para as empresas fortalecer laços subjetivos afetivos que estimulam o prazer e a funcionalidade do produto (Rindova \& Petkova, 2007).

\subsection{Design cognitivo e afetivo de produto}

O design cognitivo e afetivo de produto concebe e desenvolve produtos que aprimoram a experiência humana. Avalia os aspectos cognitivos e afetivos expressados nas opiniões e respostas no intuito de converter em requisitos do produto. Assim, através da tradução dos requisitos de resposta em atributos de produto, busca estimular a percepção do consumidor por meio de diferentes tipos de atributos "cognitivos" e "afetivos", no ciclo de projeto de produto (Rrozenfeld et al., 2006).

O design afetivo de produto explora os aspectos mais afetivos entre produto e consumidor, como propõem Diego-Mas \& Alcaide-Marzal (2016), Khalid \& Helander (2006), Khalid (2006), Khalid \& Helander (2004), Seva et al. (2011) e Seva \& Helan-der (2009). O design cognitivo-emocional de produto propõe uma abordagem mais sentimental, visceral e hedônica, como é sugerido em Crilly et al. (2004), Karim et al. (2017) e Wrigley (2013). Outras abordagens (e.g., Artacho-Ramírez et al., 2008; Li et al., 2014; Rindova \& Petkova, 2007) misturam elementos de inovação no design cognitivo.
Há ainda abordagens de design de experiência afetiva-cognitiva de pro-duto com um viés de experiência do usuário (e.g., Jiao et al., 2017; Zhou et al., 2013). Os estudos compartilham problemas comuns em relação a complexidade de avaliar e traduzir a experiência de produto (Schifferstein \& Hekker, 2011), conforme mostra a figura 1.

Figura 1: Avaliação e tradução da experiência subjetiva de produto

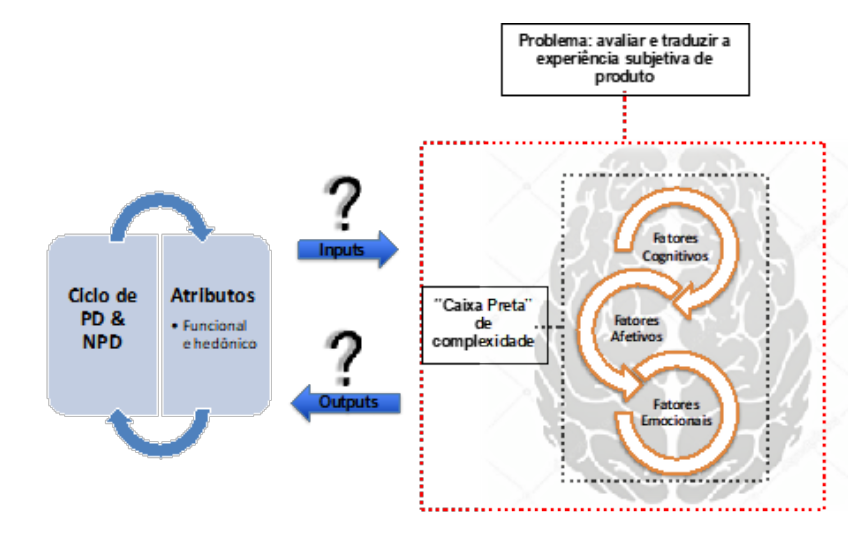

Fonte: Autor, 2019

O product design (PD) e o new product development (NPD) concebem e desenvolvem produtos com atributos que buscam estimular a percepção sensorial e os processos cognitivos e afetivos do usuário ou consumidor. O problema está em en-tender como os atributos do produto (inputs) são "percebidos e processados" por fatores cognitivos e afetivos que integram a experiência de produto, por meio da tradução de opiniões e respostas (outputs) em requisitos de engenharia.

\subsection{A complexidade da "caixa preta" da experiência de produto}

A mente humana é composta essencialmente por dois sistemas; um cognitivo e outro afetivo (Kahneman, 2011; Kahneman \& Tversky, 1979). O processamento de informações pelos sistemas não é aberto, mas fechado a própria experiência subjetiva. É uma "caixa preta" (figura 2) não acessível à engenheiros, designers e desenvolvedores. A experiência de produto é resultado do processamento das informa-ções pelos sistemas cognitivo e o afetivo. São de difícil entendimento, avaliação e tradução.

Figura 2: Sistemas cognitivo e afetivo

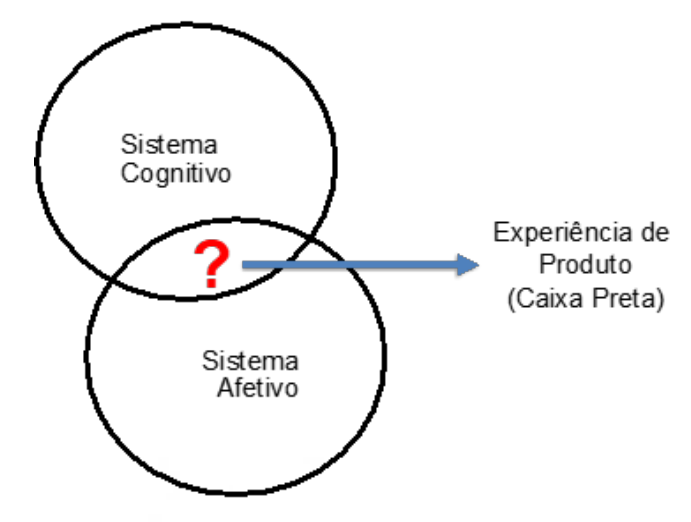

Fonte: Autor, 2019

Notas: Baseado em Kahneman (2011), Kahneman \& Tversky (1979) e Schifferstein \& Hekker (2011). HFD, v.9, n 18, p. 126-149, dezembro 2020 
Para Wrigley (2013), 80\% da vida de um indivíduo é consumida por suas emoções enquanto que outros $20 \%$ são controlados pelo seu intelecto. Emoções influenciam diretamente uma variedade de respostas cognitivas e a pesquisa sobre os efeitos emocionais nas escolhas de produto é importante e pouco estudado por designers e desenvolvedores de produto (Wrigley, 2013; Hirschman \& Stern, 1999). Além da complexidade de entender a experiência subjetiva, há um outro desafio: afeto e cognição são tratados, há muito tempo e por muito estudiosos, entidades independentes em psicologia (Zhou et al., 2013; Zajonc, 1980), o que leva a muitos desentendimentos por equipes de design de produto sobre o comportamento do consumidor. É uma deficiência da psicologia a separação da emoção e cognição (Khalid \& Helander, 2006; Vygotsky, 1962). Ellsworth \& Scherer (2003) apontam que enquanto o afeto referese a respostas sentimentais a cognição é utilizada para in-terpretar, compreender e entender a experiência.

Norman (2004) defende que o sistema cognitivo dá sentido ao mundo enquanto que o sistema afetivo é crítico em relação a ele. Ambos se complementam e cada sistema influencia o outro com a cognição proporcionando afeto e sendo afetada por ele (Crilly et al., 2004; Coates, 2003; Ashby et al., 1999). Khalid \& Helander (2006) afirmam que o consumidor percebe a realidade de um modo afetivo (intuitivo e experiencial) e cognitivo (analítico e racional), e separar a emoção da cognição é uma grande deficiência da psicologia e da ciência cognitiva em geral. Emoções não são a causa do pensamento racional, mas podem motivar o interesse pela objetivi-dade. O pensamento racional impacta os sentimentos e o pensamento afetivo im-pacta a cognição.

Jiao et al. (2017) apontam que o recente consenso sobre a integração do afe-to e cognição nas avaliações de produto é conduzido pelo próprio acoplamento ín-timo das intenções e decisões dos consumidores. Os processos que ocorrem até o julgamento e escolha do consumidor e os fatores que afetam essas decisões variam de um modelo para outro (Diego-Mas \& Alcaide-Marzal, 2016; Crilly et al., 2004; En-gel et al., 1995; Han \& Hong, 2003). Métodos já foram propostos na tentativa de de-terminar a resposta do usuário sem uma avaliação verbal (Ho \& Lu, 2014; Lu \& Peti-ot, 2014), no entanto sempre com a suposição ou simulação do que ocorre dentro da "caixa preta". Para Picard et al. (2004), a extensão da teoria cognitiva em explicar e explorar o papel do afeto na experiência subjetiva ainda está em sua infância in-vestigativa. As pesquisas de Khalid (2006), Khalid \& Helander (2004) e Khalid \& Helander (2006) trouxeram avanços significativos para o entendimento da "caixa preta" da experiência de produto; e sobre o processamento dos sistemas afetivo e cognitivo identificados pelos autores como sistemas rápido e lento, respectivamente.

\subsection{Sistemas analítico "Iento" e experiencial "rápido"}

É entendido e aceito que há dois sistemas em ação durante a experiência de produto: um "analítico" e mais cognitivo; e outro "experiencial" e mais afetivo (figura 2). Epstein (1994) enfatiza que a tomada de decisão racional depende das habilida-des analíticas e cognitivas que operam em modo lento. Slovic et al. (2002) conside-ram que o "sistema analítico" ou cognitivo e racional utiliza algoritmos e regras nor-mativas como cálculos de probabilidade, lógica formal e avaliação de risco. Suge-rem que é relativamente lento, esforçado e que requer controle consciente da men-te. $O$ "sistema experiencial" ou afetivo é rápido, intuitivo e quase automático, e não se dá no nível consciente do consumidor. Quando uma pessoa procura responder a um evento, há uma busca automática e uma correspondência com a base de dados de memórias inspiradas em experiências passadas. A mente procura em um banco de memórias passadas, um histórico de eventos relacionados ao evento atual, in-cluindo a valência emocional e as implicações do ocorrido.

\section{PRESSUPOSTOS, CONSTRUCTOS E COMPONENTES DO MODELO}

Este estudo considera que afeto e cognição são interdependentes e portanto devem ser "integrados" nas aplicações de design de produto, pois os próprios fenômenos são integrados (Zhou et al., 2013; Parrott \& Sabini, 1989). Descobertas laboratoriais e a observação cotidiana sugere a unidade e inter-relação destes proces-sos, e tentar dissecá-los em faculdades separadas negligencia a riqueza da vida mental como apontam Damasio \& Adolphs (2001) e Storbeck \& Clore (2007). Este estudo considera também que a experiência de produto é resultado do fluxo de pro-cessamento informacional pelos sistemas cognitivo e afetivo.

Os pressupostos são apresentados na forma de constructos conceituais: i) Atributos "cognitivos" e funcionais, e "afetivos" e hedônicos de produto; ii) Sistemas "cognitivo e afetivo" integrado nas avaliações; iii) Experiência "cognitiva e afetiva" de produto; e iv) Requisitos "cognitivos e afetivos" de resposta do consumidor. Se desdobram os componentes que fornecem a base do modelo (tabela 1). 


\begin{tabular}{|c|c|}
\hline Constructos conceituais & Componentes cognitivos \\
\hline $\begin{array}{l}\text { i. Atributos "cognitivos" e funcionais, } \\
\text { "afetivos" e hedônicos de produto. } \\
\text { Pressupostos: produtos devem ofere- } \\
\text { cer atributos hedônicos e funcionais; } \\
\text { produtos devem ser fáceis e prazero- } \\
\text { sos; a facilidade de compreensão pro- } \\
\text { voca emoções positivas, enquanto } \\
\text { que a dificuldade provoca emoções } \\
\text { negativas. }\end{array}$ & $\begin{array}{l}\text { Estímulo Externo (1): São inputs origina- } \\
\text { dos no produto, mais especificamente } \\
\text { nos atributos do produto. }\end{array}$ \\
\hline $\begin{array}{l}\text { ii. Sistemas "cognitivo e afetivo" inte- } \\
\text { grado nas avaliações. Pressupostos: } \\
\text { cognição e emoção estão interligadas } \\
\text { no processo de percepção de um pro- } \\
\text { duto; a cognição interpreta e compre- } \\
\text { ende enquanto afeto julga a experiên- } \\
\text { cia; os sistemas cognitivo e afetivo se } \\
\text { integram na análise subjetiva e to- } \\
\text { mada de decisão. } \\
\text { iii. Experiência "cognitiva e afetiva" } \\
\text { de produto. Pressupostos: o sistema } \\
\text { afetivo e automático domina o sis- } \\
\text { tema cognitivo e pensativo; vieses } \\
\text { heurísticos afetivos são mais rápidos e } \\
\text { intuitivos que as deciõos racionais } \\
\text { cognitivas que são mais lentas e analí- } \\
\text { ticas. }\end{array}$ & $\begin{array}{l}\text { Estímulo Interno (2): A percepção senso- } \\
\text { rial detecta o estímulo originado no pro- } \\
\text { duto por meio da instrução (pergunta). A } \\
\text { percepção sensorial e cognitiva inicia o } \\
\text { processamento lento e analítico, inter- } \\
\text { pretação e compreensão do produto que } \\
\text { é sobreposta pelo sistema afetivo rápido } \\
\text { e intuitivo, mais rápido, que vivencia a ex- } \\
\text { periência. } \\
\text { Resposta Interna (3): Este momento de- } \\
\text { fine como será a experiência subjetiva } \\
\text { que ocorre a partir dos vieses heurísticos } \\
\text { com base no banco em crenças, afetos e } \\
\text { emoções. Determina se a experiência de } \\
\text { produto será positiva ou negativa. Se } \\
\text { desdobram em experiências subjetivas } \\
\text { visceral e estética (afetivas), comporta- } \\
\text { mental e semântica (cognitivas), simbó- } \\
\text { lica e reflexiva (afetiva e cognitiva). Deter- } \\
\text { minam a intenção de compra do consu- } \\
\text { midor ao realizar associações e compara- } \\
\text { ções automáticas no banco de memórias } \\
\text { de experiências anteriores. }\end{array}$ \\
\hline $\begin{array}{l}\text { iv. Requisitos "cognitivo e afetivo" de } \\
\text { resposta do consumidor. Pressupos- } \\
\text { tos: respostas emocionais são predito- } \\
\text { res da intenção de compra; respostas } \\
\text { cognitivas tem elementos de impres- } \\
\text { são estética, interpretação semântica } \\
\text { e associação simbólica; requisitos cog- } \\
\text { nitivos podem ser classificados em vis- } \\
\text { cerais, comportamentais e reflexivos; } \\
\text { necessidades e preferências afetivas e } \\
\text { emocionais (hedônicas) operam como } \\
\text { heurísticas de tomada de decisão e di- } \\
\text { recionam o viés intencional; é possível } \\
\text { identificar o viés de percepção subje- } \\
\text { tiva do consumidor. }\end{array}$ & $\begin{array}{l}\text { Resposta Externa (4): são respostas ex- } \\
\text { ternas consideradas requisitos de res- } \\
\text { posta do consumidor. Os requisitos se- } \\
\text { guem o entendimento do CogPO, e re- } \\
\text { presentam indicadores de: cognitividade } \\
\text { (dificuldade ou facilidade); a afetividade } \\
\text { (desagradabilidade ou agradabilidade); } \\
\text { a intencionalidade de compra produto } \\
\text { que influencia a decisão de compra. }\end{array}$ \\
\hline
\end{tabular}

Fonte: Autor, 2019

A tabela 1 apresenta os constructos conceituais, pressupostos e componentes que fornecem suporte teórico e metodológico ao modelo conceitual.

\subsection{Constructos conceituais e pressupostos}

\subsubsection{Atributos cognitivos e afetivos de produtos}

O primeiro pressuposto é que produtos têm atributos funcionais e hedônicos. Khalid \& Helander (2006), Khalid (2006) e Khalid \& Helander (2004) investigam os aspectos funcionais e hedônicos (holísticos e de estilo) e propõem a "hedonomia" como um novo campo de pesquisa em design. Sugerem que o consumidor tem uma experiência subjetiva ao interagir com o produto. As respostas do consumidor são carregadas de elementos cognitivos e afetivos, pois são o resultado do funcionamento integrado dos sistemas cognitivo e afetivo (figura 1). Os estudos de Khalid \& Helander (2006) confirmam que produtos desconhecidos são avaliados preferencialmente por atributos holísticos, e produtos conhecidos são avaliados preferencialmente por atributos de estilo e funcionalidade. Evidências apontam que para produtos que apresentam novidades, atributos holísticos e de estilo são estatisticamente mais importantes do que atributos funcionais.

Seva \& Helander (2009) e Seva et al. (2011) entendem que a escolha depen-de de vários fatores, pois inclui todas as dimensões afetivas, perceptuais e compor-tamentais do consumidor. Há evidências significativas de que atributos estéticos e funcionais interferem na intenção de compra do consumidor. Em experimento reali-zado com telefones celulares que ficam mais finos (considerado um atributo estéti-co) e pesados (considerado um atributo funcional) a emoção do consumidor é esti-mulada (Seva $\&$ Helander, 2009). Além disso, os resultados confirmam diferentes tendências de preferência em diferentes culturas. Nos estudos apresentados os cingapurianos são afetados por atributos funcionais enquanto os Filipinos são afe-tados por atributos estéticos. Concluem, da mesma forma que Khalid (2006), que a intenção de compra do consumidor é diferente em diferentes culturas e apresenta diferentes tendências. Assim, a experiência emocional é provocada por diferentes tipos de atributos em cada local, além do impacto emocional ser um preditor da in-tenção de compra do consumidor.

Para Seva et al. (2011), as respostas em relação à aparência do produto se dividem em três dimensões: impressão estética, interpretação semântica e associação simbólica. A impressão estética refere-se ao apelo da beleza do produto ou uma resposta sobre a atratividade. Consumidores têm diferentes interpretações que dependem de suas intuições, sentimentos e preferências estéticas, como afirma Crilly et al. (2004). A interpretação semântica descreve o que um produto transmite por sua função ou modo de uso. É a mensagem a ser transmitida ao consumidor e para isso relaciona atributos do produto com o comunicado sobre si ou sobre o contexto de uso. O objetivo do design semântico do produto é a percepção dos consumido-res. A associação simbólica baseia-se no que um produto diz sobre o proprietário e não sobre si mesmo. Inclui o apego de indivíduos ao produto em termos de seu sig-nificado pessoal e social e, portanto, a representação mental e simbólica do que é percebido no produto.

\subsection{2 "Sistemas cognitivo e afetivo" integrado nas avaliações de produto}

O segundo pressuposto é o entendimento, por engenheiros e designers, da integração dos sistemas cognitivo e afetivo nas avaliações de produto. Na visão de 
Norman $(1988,2004)$, quando o consumidor analisa o produto há uma sequência de processos que segue uma hierarquia de níveis afetivos e cognitivos. São descri-tos como níveis visceral, comportamental e reflexivo. Primeiro, o consumidor tem uma como níveis visceral, comportamental e reflexivo. Primeiro, o consumidor tem uma observar o produto. Em segundo, tem uma experiência comportamental ao avaliar a usabilidade e o desempenho. Em terceiro, tem uma experiência reflexiva mais Os três níveis compõem em diferentes medidas os sistemas cognitivo e afetivo. Aftab \& Rusli (2017) confirmam a hierarquia de abstração de Norman (2004) por meio de experimentos de avaliação (design de móveis usados). A maioria dos parti-cipantes são emocionalmente ligados à usabilidade (nível comportamental) e à apa-rência (nível visceral) dos móveis avaliados.

Khalid \& Helander (2006) propõem um maior entendimento a respeito do cruzamento dos sistemas cognitivo e afetivo. Partem da "Prospect Theory" de Kahne-man \& Tversky (1979), que aborda os sistemas de tomada de decisão e vieses heu-rísticos de afetividade como mais fortes que a decisão cognitiva e racional. As con-clusões são que as emoções influenciam as decisões de compra do consumidor exatamente como os vieses heurísticos afetivos se sobrepõem a decisões racionais e, possivelmente, as determinam.

Wrigley (2013) parte da representação de Crilly et al. (2004) sobre a hierar-quia de percepção estética, semântica ou funcional, e simbólica do produto. Contu-do, busca avançar a pesquisa sobre o design cognitivo e emocional incorporando ao framework de Crilly et al. (2004) a terminologia emocional de Norman (2004) so-bre aspectos viscerais, comportamentais e reflexivos do design de produto. $O$ pro-cessamento em viscerais, comportamentais e reflexivos do design de produto. O pro-cessamento em mundo e do que acontece nele (afetivo), e a interpretação do que acontece (cognitivo) Há, portanto, dois sistemas em operação; o afetivo e o cogniti-vo.

Rindova \& Petkova (2007) explicam a dinâmica da cognição e da emoção na percepção de valor do consumidor. Fornecem um enfoque de cognição e emoção interligadas no processo de formação da percepção de valor de um produto inovador. Fornecem uma dinâmica emocional associada ao processo de resolução da incongruência (dificuldade de uso do produto) que leva a um ciclo recursivo no qual: as emoções positivas aumentam a compreensão, o que aumenta as emoções positivas; as emoções negativas aumentam o ceticismo, o que leva a mais frustra-ção e rejeição. Resumindo, a cognição entende e compreende o que está sendo percebido pelos sentidos sensoriais, enquanto que o afeto promove o sentimento de aprendi-zagem e experiência durante a interação. Este entendimento acompanha as pro-postas de Crilly et al. (2004), Khalid \& Helander (2006), Norman (1988) e Wrigley (2013). Há dois sistemas em operação, o afetivo e o cognitivo e ambos funcionam juntos um influenciando o outro e vice-versa. Capacidades cognitivas interpretam os inputs da experiência de produto e provocam memórias afetivas, evocando asso-ciações com outros produtos (Schifferstein \& Hekker, 2011)

\subsubsection{Experiência "cognitiva e afetiva" de produto}

O terceiro pressuposto é a necessidade de maior entendimento sobre a experiência subjetiva do consumidor, experiência de interação, experiência de uso, to-das associadas neste artigo à experiência de produto. Zhou, Ji \& Jiao (2013) e Jiao et al. (2017) buscam entender como a experiência subjetiva e os estados afetivos influenciam o comportamento de escolha sob incerteza.

Há dois aspectos importantes em relação à experiência de produto; primeiro a experiência interna e subjetiva de usar ou consumir o produto que é influenciada pela memória de experiência anterior, de aprendizado. Karim et al. (2017) afirmam a importância da experiência subjetiva em resultados de pesquisa de avaliação da intenção de compra dos consumidores. Mostram que alguns produtos induzem sentimentos de prazer mais fortes em comparação com outros. Confirmam que determinados produtos induzem avaliações mais fortes de prazer em mulheres que em homens em produtos com expressões faciais. Concluem que avaliar e traduzir a experiência de produto em diferentes culturas e gêneros é recurso essencial para o design de produto.

Seguindo os entendimentos apontados, é possível afirmar que a experiência afetiva direciona o viés subjetivo de avaliação. O consumidor associa a memória de experiências anteriores a apreensão visceral e estética imediata dos inputs. A partir delas julga se o produto é positivo ou negativo, mas ainda em níveis pré-reflexivos, ou seja, afetivos. Após associações semânticas, simbólicas e reflexivas há a refle-xão com viés subjetivo sobre a decisão. A reflexão é cognitiva e exige esforço e car-rega toda a carga de seu viés subjetivo afetivo. O funcionamento deste processo é interno, subjetivo e fechado ao observador externo. Portanto, só pode ser suposto ou inferido em análises e testes empíricos.

\subsubsection{Requisitos "cognitivos e afetivos" de resposta do consumidor}

O quarto pressuposto é a importância da abordagem multidisciplinar para esclarecer as opiniões e respostas do consumidor em relação ao design cognitivo e afetivo de produto. Neste caso, explicações da neurociência e das ciências cognitivas. Para Maturana \& Varela (1987), se o objetivo é compreender qualquer atividade humana é necessário prestar atenção para a emoção que define o domínio das ações no qual aquela atividade acontece e, neste processo, aprender a ver quais ações são desejadas pela emoção. Intenções se iniciam em processos subjetivos emocionais e afetivos internos e após, refletidas ou não, são expressadas.

Wrigley $(2011 ; 2013)$ relata que elementos de resposta da "cogniçãoemocio-nal" não são apresentados como qualidades objetivas de um produto. Pelo contrá-rio, são uma interpretação cognitiva das qualidades de um objeto conduzidas tanto pela percepção de estímulos tangíveis quanto por fatos relembrados da memória e da emoção do consumidor. A resposta afeta os músculos faciais e a estrutura mus-culoesquelética, as vísceras e o meio interno do corpo, bem como as respostas neu-roquímicas no cérebro e fazem parte do modo pelo qual o estado interno do corpo é modificado pelas emoções. Uma descrição parecida é feita por Damasio (2001). Pa-ra Damasio \& Adolphs (2001) a resposta instintiva, visceral ou imediata à informa-ção sensorial influenciam fortemente as informações secundárias, adquiridas quando ocorre interação cognitiva comportamental e reflexiva posterior. Assim, há uma hierarquia de processos internos em operação. Embora afeto e cognição se-jam, em determinado grau, sistemas neuroanatomicamente distintos, eles estão pro-fundamente interligados, com cada sistema influenciando o outro (Ashby et al., 1999; Norman, 2004; Crilly et al., 2004) Fazem parte de uma mesma experiência, conhecida no campo da filosofia da mente pelo termo de "qualia" fenômeno da "consciência" humana. 
Independentemente do consenso de que cognição e afeto e sejam integrados, é um desafio criar e desenvolver modelos e métodos analíticos rigorosos para se descobrir as necessidades e preferências afetivas e cognitivas do consumidor. É um desafio medir a experiência subjetiva, identificar as relações e mapear o fluxo entre a experiência e os elementos do design de um produto, conforme aponta Fu-kuda (2011)

\subsection{Componentes do modelo}

\subsubsection{Cognição e afeto}

Um importante componente do modelo é o fator cognição. Cognição costuma ser o termo científico utilizado para significar o processo de pensamento. A psicologia e as ciências cognitivas utilizam o termo cognição para se referir a uma visão de processamento de informações das funções psicológicas de um indivíduo. Outras interpretações ligam a cognição ao estudo de toda atividade humana relacionada ao conhecimento. Essas atividades incluem a atenção, criatividade, memória, percepção, resolução de problemas, pensamento e o uso da linguagem (Wrigley, 2013; Neisser 2009).

A psicologia cognitiva amplia a compreensão do fenômeno sobre emoção e cognição. Cognição se relaciona diretamente com a emoção, e Norman (2004) define o domínio da cognição emocional como o nível do pensamento cognitivo que lida com as respostas emotivas. Para Norman, a cognição emocional pode ser pensada como um processamento subjetivo, mas racional do estímulo, da experi-ência, da informação e do conhecimento do dia-a-dia que engloba ou permite a tomada de decisão, ação e resposta. O cognitivismo substitui o behaviorismo como a teoria da aprendizagem dominante no final da década de 1950 e início da déca-da de 1960 (Ertmer \& Newby, 2013). Enfatiza o papel das atividades "mentais" no processo de aprendizagem e inclui ações como pensar, lembrar, perceber, inter-pretar, raciocinar e resolver problemas (Pritchard, 2014)

\subsubsection{Ontologia do paradigma cognitivo (CogPO)}

A partir do paradigma cognitivista é aceito e inferido que os tipos de atributos de um produto estimulam a percepção do consumidor que, ao perceber e processar os inputs, responde com ações e respostas comportamentais, ou outputs. O conceito de "estímulo" é utilizado em diferentes domínios científicos e de maneiras geralmente semelhantes. Qualquer coisa pode ser um estímulo já que qualquer coisa pode suscitar uma resposta ao estímulo. Para Turner \& Laird (2012), estímulos são todas as coisas que produzem uma resposta a partir de uma instrução. Há dois subtipos imediatos de estímulos que são indicados e utilizados dentro da ontologia do paradigma

${ }^{1}$ Qualidades intrínsecas da mente humana (Tavares, 2018).

2 http://brainmap.org/ acessado pela última vez no dia 01/12/2019. cognitivista (CogPO), apresentado por Turner \& Laird (2012): o estímulo ex-plícito e o estímulo implícito. O estímulo explícito, que é normalmente gerado sob o controle do experimentador e existe externamente ao usuário, é identificado ao estímulo externo. E o estímulo implícito, que é processado internamente pelos sis-temas cognitivos e afetivos durante a experiência subjetiva, é identificado ao estímulo interno.

O CogPO é desenvolvido a partir da taxonomia criada para o banco de dados do BrainMap (http://brainmap.org//2) ${ }^{2}$ Procura representar os estímulos, instruções e respostas que definem as condições de um experimento em um formato padroniza-do e flexível, com termos e relações bem definidas. É uma das várias ontologias li-gadas à engenharia do conhecimento e esforços de integração de informação que trabalham em conjunto para raciocinar sobre a relação entre estrutura e função do cérebro. Instruções são a entidade portadora de informações que estabelece as re-gras para o comportamento desejado dos sujeitos, ou seja, as respostas. É uma di-reção explícita que orienta o comportamento durante as condições do experimento. A sequência dos eventos, considerados a partir do entendimento do CogPO, é apresentada na figura 3.

Figura 3: Sequência de eventos cognitivos explicados pelo CogPO

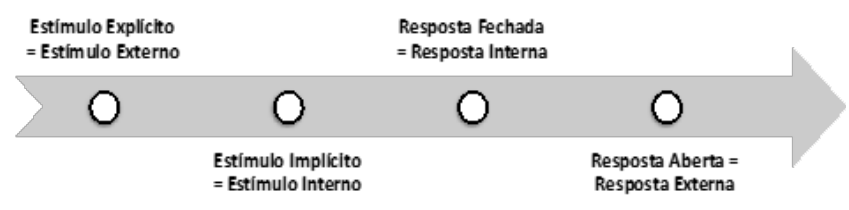

Fonte: Autor, 2019

Notas: Adaptado do CogPO, apresentado em Turner \& Laird (2012).

O wiki do CogPO (www.wiki.cogpo.org) ${ }^{3}$ permite a visão completa do proces-so. Parte de uma extensa base de dados sobre psicologia experimental e neuroci-ência cognitiva disponíveis em um banco de dados compartilhado. De acordo com o CogPO, uma resposta pode ser uma resposta aberta, expressa por uma parte do corpo que é observável externamente (um pressionamento de botão ou movimento ocular, por exemplo), que é identificado como a resposta externa (figura 3). Ou ainda, uma resposta secreta, executada internamente como um ensaio silencioso de nomear objetos, que é identificado como resposta interna. Uma resposta é considerada uma combinação de processos que se desdobram ao longo do tempo e são avaliados ou medidos. A modalidade que cada resposta externa têm é a parte ou expressão do corpo usada na resposta, assim como a opinião do participante do experimento.

Respostas internas (experiência subjetiva, interna e inicialmente não-verbalizada) e as respostas externas (respostas verbalizadas ou assinaladas, opiniões, expressões e ações) são considerados os requisitos de resposta do consumi-dor. Os requisitos são essenciais para a tradução pela equipe de engenharia e de-sign de produto em atributos que partem, necessariamente, da avaliação da experiência subjetiva do consumidor.

${ }^{3}$ www.wiki.cogpo.org acessado pela última vez no dia 01/12/2019 


\subsubsection{Framework de avaliação da experiência cognitiva e afetiva de Produto}

Com os pressupostos, constructos e componentes cognitivos adequados e sistematizados por meio do CogPO, busca-se inovar e avançar no processo de e avaliação e tradução da experiência cognitiva e afetiva de produto e trazer, dessa forma, um modelo conceitual que propõe novos requisitos de respostas dos consu-midores para apreciação da equipe de engenharia e design de produto. Os requi-sitos são resultados do fluxo de experiência.

Figura 4: Framework de avaliação da experiência cognitiva e afetiva de produto

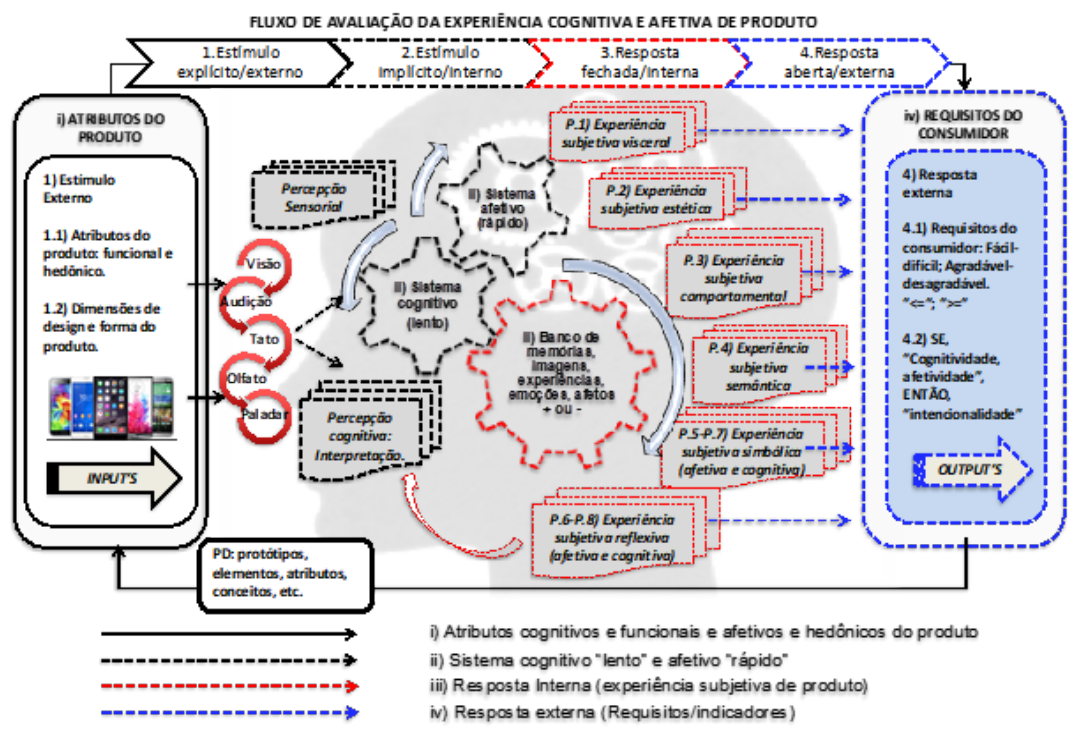

Fonte: Autor, 2019

A figura 4 descreve o fluxo de avaliação da experiência cognitiva e afetiva de produto, assim como a hierarquia de processos e sistemas cognitivos e afetivos em acordo com a literatura estudada (Crilly et al., 2004; Khalid \& Helander, 2004; Norman, 2004; Wrigley, 2011; Zhou et al., 2013). O framework é desenvolvido res-peitando essa hierarquia de processos internos e adequado à ontologia de para-digma cognitivista (CogPO). Segue, portanto, os 4 componentes do CogPO apresentados na tabela 1, e é composto por 4 momentos.

A primeira etapa se inicia com o (1) Estímulo externo, identificado como inputs causados pelos atributos de produto (1.1), que podem ser funcionais e holísticos ou hedônicos, e serão avaliados pelo consumidor através de suas dimensões e formas (1.2).

A segunda etapa descreve a percepção sensorial e cognitiva do consumidor, no qual o estímulo explícito é recebido internamente, de maneira implícita, o que provoca o (2) Estímulo interno, um processo de percepção e avaliação dos inputs do produto pelos sistemas cognitivo e "lento" e afetivo e "rápido". O sistema afetivo predomina e processa o banco de memórias, imagens e experiências anteriores do consumidor fornecendo valência positiva ou negativa à experiência como resultado da interação.

A terceira etapa descreve a (3) Resposta interna, identificados com as experiências subjetivas visceral (P.1), estética (P.2), comportamental (P.3), semântica (P.4) simbólica (P.5-P.7) e reflexiva (P.6-P.8). Já estão organizadas na forma de perguntas "P.s" que serão direcionadas, no modelo proposto, a cada nível de experiência subjetiva. Entende-se que a soma das experiências subjetivas integram a experiência de produto um resultado do processamento dos inputs pelos sistemas cognitivo e afetivo de maneira integrada, sem separação ou diferenciação. As respostas resultam, portanto, das instruções ou perguntas direcionadas aos processos específicos de cada nível de experiência.

A quarta e última etapa descreve a (4) Resposta externa ou os outputs identificados e associados com os requisitos de resposta do consumidor $(4.1,4.2)$. São propostos como requisitos as opiniões derivadas da experiência subjetiva: i) "afetiva" (visceral e estética), ii) "cognitiva" (comportamental e semântica), e iii) "afetivocognitiva" (simbólica e reflexiva) em relação ao design "funcional" e "hedônico" de produto. Um dos objetivo é unir aspectos "cognitivos e afetivos" do consumidor ao design "cognitivo e afetivo" do produto, representados dentro de um contexto de experiência de produto que une o encontro das partes. Os resultados são apresentados na forma de três indicadores: i) indicador de cognitividade, que mede aspectos cognitivos ou de funcionalidade do produto; ii) indicador de afetividade, que mede aspectos afetivos ou de agradabilidade e prazer do produto; e iii) indicador de intencionalidade, que mede a relação existente entre os indicadores de cognitividade e afetividade.

\section{MODELO DE AVALIAÇÃO E TRADUÇÃO}

As opiniões e respostas do consumidor são o requisitos resultado da experi-ência de produto. São expressados pelo consumidor a partir de sua percepção em relação às instruções-perguntas direcionadas aos atributos avaliados, neste caso atributos de produto funcionais e "cognitivos" e hedônicos e "afetivos". As opiniões contém elementos cognitivos e afetivos e são, portanto, resultantes da experiência subjetiva que parte dos níveis de hierarquia: visceral e estética, comportamental e semântica, simbólica e reflexiva. São propostos na forma de indicadores, conforme é mostrado na figura 5.

Figura 5: Modelo conceitual de avaliação e tradução da experiência cognitiva e afetiva de produto

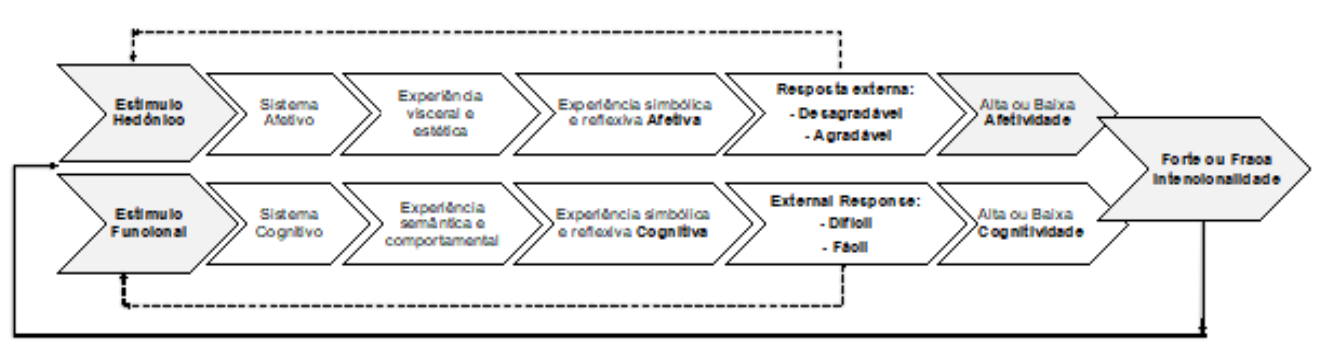

Fonte: Autor, 2019

O atributo ou estímulo hedônico demanda o sistema afetivo, e produz uma resposta sobre a agradabilidade ou desagradabilidade de usar ou consumir o pro-duto. É o resultado da experiência afetiva visceral e estética, depois simbólica e re-flexiva, e representa $o$ indicador de afetividade. $O$ atributo ou estímulo funcional demanda - sistema cognitivo e produz uma resposta sobre a facilidade ou dificul-dade de se usar ou consumir o produto. É o resultado da experiência cognitiva comportamental e semântica, depois simbólica e reflexiva, e representa o indicador de cognitividade.

HFD, v.9, n 18, p. 126-149, dezembro 2020 
As experiências tanto a afetiva quanto a cognitiva são acompanhadas pela experiência subjetiva simbólica e reflexiva, pois são compostas por processos mais elevados da "mente humana" e pertencem a níveis hierárquicos tardios (Crilly et al. 2004; Norman, 1988; Seva et al., 2011; Wrigley, 2013). Estão, portanto, no final do processo de julgamento e discernimento da experiência de produto.

\subsection{Validação dos Experts}

O modelo proposto foi apresentado para análise e sugestão de 6 profissionais da área de engenharia e design de produtos ${ }^{4}$. As sugestões de melhorias, assim como a descrição das implementações ao modelo conceitual, são apresentadas na tabela 2.

Tabela 2: Sugestões e melhorias do modelo de avaliação

\begin{tabular}{|c|c|}
\hline $\begin{array}{l}\text { a) Inversão das escalas de medição para } \\
\text { atributos funcionais e "cognitivos" e hedô- } \\
\text { nicos e "afetivos". }\end{array}$ & $\begin{array}{l}\text { - Para aspetos cognitivos a medição das } \\
\text { opiniões em escalas de difícil (1) à fácil (10); } \\
\text { e dos aspectos afetivos a medição das opi- } \\
\text { niôes em escalas de desagradável (1) à agra- } \\
\text { dável (10). }\end{array}$ \\
\hline $\begin{array}{l}\text { b) Apontamentos sobre os aspectos visce- } \\
\text { ral e estético serem a mesma coisa para o } \\
\text { usuário comum. }\end{array}$ & $\begin{array}{l}\text { - Optou-se por manter as diferentes per- } \\
\text { guntas no intuito de buscar avaliar a expe- } \\
\text { riência subjetiva com um maior grau de as- } \\
\text { sertividade, considerando as hierarquias } \\
\text { propostas por (Crilly et al., 2004; Khalid \& } \\
\text { Helander, 2004; Wrigley, 2013). }\end{array}$ \\
\hline $\begin{array}{l}\text { c) Apontamentos sobre o aspecto estético } \\
\text { interferir no aspecto funcional do produto. }\end{array}$ & $\begin{array}{l}\text { - Informação importante para a validação } \\
\text { do modelo que considera os aspectos em } \\
\text { diferentes niveis de avaliação da experiên- } \\
\text { cia cognitiva e afetiva do consumidor. }\end{array}$ \\
\hline $\begin{array}{l}\text { d) Separação das perguntas direcionadas } \\
\text { aos aspectos funcionais e mais "cognitivos" } \\
\text { e estéticos e mais "afetivos" dos produtos. }\end{array}$ & $\begin{array}{l}\text { - Verificado na associação, conforme pro- } \\
\text { posta no modelo, de atributos funcionais } \\
\text { serem medidos por escalas cognitivas (difí- } \\
\text { cil à fácil), e atributos estéticos por escalas } \\
\text { afetivas (desagradável à agradável). }\end{array}$ \\
\hline $\begin{array}{l}\text { e) Preocupação dos usuários com suas res- } \\
\text { postas anteriores na aplicação do modelo. }\end{array}$ & $\begin{array}{l}\text { - Foi ajustado o texto e o tamanho da per- } \\
\text { gunta, para que ficasse em acordo com as } \\
\text { proposições do modelo conceitual. }\end{array}$ \\
\hline $\begin{array}{l}\text { f) Proximidade semântica de algumas per- } \\
\text { guntas. }\end{array}$ & $\begin{array}{l}\text { - Resolvido com a aplicação de diferentes } \\
\text { escalas de medição para avaliaçấo das di- } \\
\text { mensões cognitiva e afetiva separada- } \\
\text { mente. }\end{array}$ \\
\hline $\begin{array}{l}\text { g) Misturar a ordem dos produtos durante } \\
\text { os experimentos. }\end{array}$ & - A ser considerado nas aplicações. \\
\hline $\begin{array}{l}\text { h) Aumentar o tamanho das imagens. } \\
\text { i) As pessoas começam a comparar os pro- } \\
\text { dutos. }\end{array}$ & $\begin{array}{l}\text { - A ser considerado nas aplicações. } \\
\text { - A ser considerado nas aplicações. }\end{array}$ \\
\hline $\begin{array}{l}\text { j) Mudar as perguntas durante } \circ \text { experi- } \\
\text { mento. }\end{array}$ & - A ser considerado nas aplicações. \\
\hline k) Medir a percepção de facilidade de uso. & $\begin{array}{l}\text { - Direcionado a tradução dos requisitos fun- } \\
\text { cionais dos produtos. }\end{array}$ \\
\hline I) Perguntar se o usuário tem o produto. & $\begin{array}{l}\text { - A ser considerado e associado ao requisito } \\
\text { experiência de uso. }\end{array}$ \\
\hline $\begin{array}{l}\text { m) Cruzar com os produtos mais vendidos. } \\
\text { n) Utilizar produtos fáceis, como eletrodo- } \\
\text { mésticos. }\end{array}$ & $\begin{array}{l}\text { - A ser considerado nas aplicações. } \\
\text { - A ser considerado nas aplicações. }\end{array}$ \\
\hline
\end{tabular}

Fonte: Autor, 2009.
Com as sugestões foi elaborado o instrumento de avaliação e tradução que cruza as informações oriundas do produto (estímulos) com informações oriundas do consumidor (respostas) por meio das perguntas (instruções) direcionadas aos diferentes níveis de experiência de produto.

\subsection{Instrumento de avaliação e tradução das opiniões e respostas do consumidor}

A tabela 3 apresenta a matriz de avaliação dos estímulos (inputs) e respostas (outputs) por meio das instruções-perguntas, proposto como extensão ao modelo conceitual de avaliação. Considera os requisitos de entrada (inputs) os estímulos do produto, e como os requisitos de saída (outputs) as opiniões e respostas do consumidor.

Tabela 3: Matriz de avaliação e tradução das opiniões e respostas

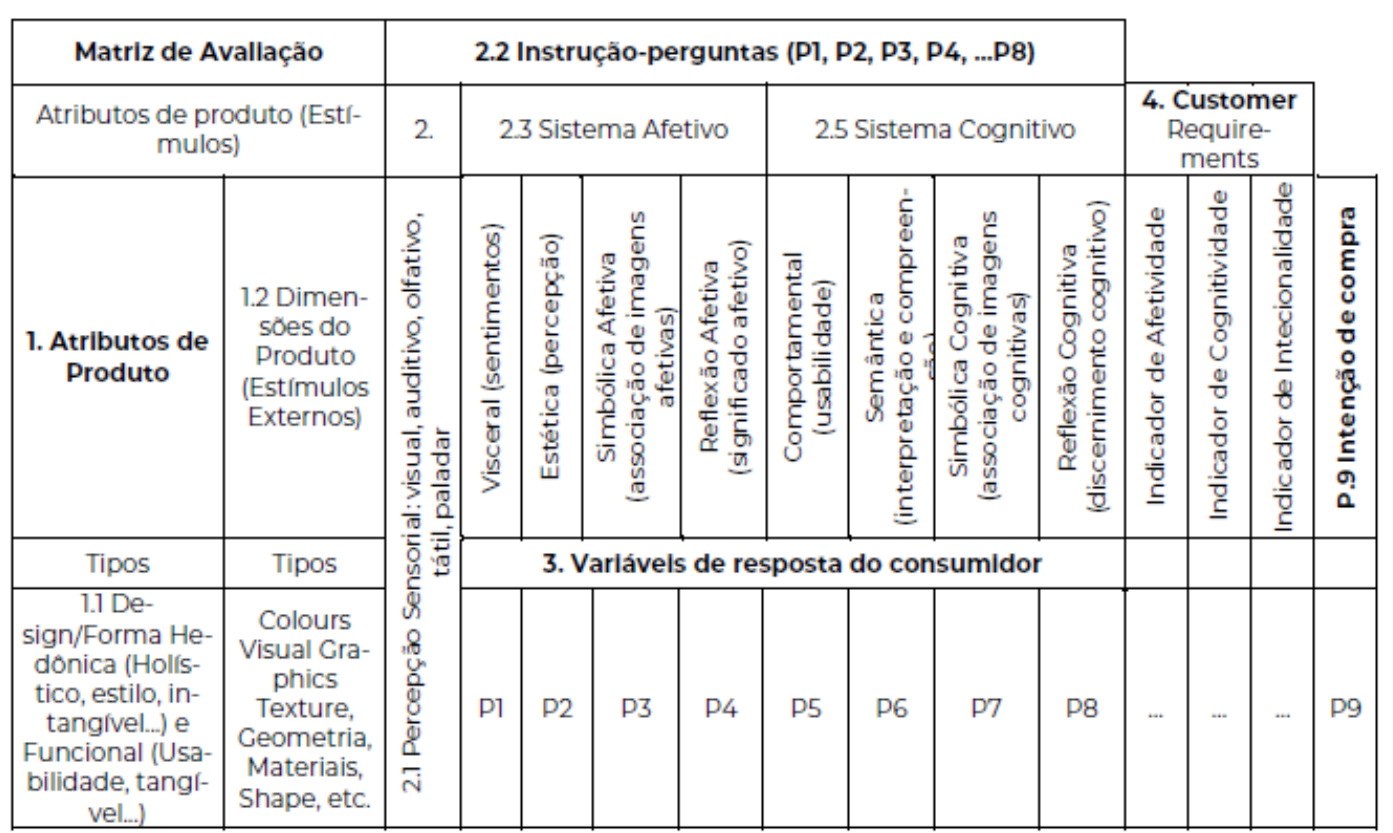

Fonte: Autor, 2019

Notas: Os "P's" (P1, P2, ...P8) indicam as instruções-perguntas, que resultam em variáveis de res-posta a cada nivel de experiência subjetiva de produto medidas nas escalas apresentadas. Cada instruçãopergunta é direcionada a uma experiência específica cognitiva ou afetiva. O objetivo é cap-turar a

opinião sobre um atributo funcional e "cognitivo" ou hedônico e "afetivo" do produto.

O modelo sugere que os atributos do produto (1), que podem ser funcionais e hedônicos (1.1), são representados por suas dimensões (1.2) que devem ser esco-lhidas antes da aplicação do modelo. São avaliadas por tipos de cor, aparência vi-sual, textura, forma, geometria, material, entre outros. É importante definir o que será avaliado durante a experiência de produto.

${ }^{4}$ O estudo e questionário foi aplicado em dezembro de 2019, na Pontifícia Universidade Católica do Paraná, com pesquisadores do Programa de Pós-Graduação em Engenharia de Produção e Sistemas. 
Ao escolher os tipos de atributos funcionais e hedônicos a serem avaliados, em seguida as atenções se voltam a percepção (2) ou canal de tradução dos inputs para o início da experiência. Um sentido de percepção sensorial (2.1) é escolhido (visão, audição, olfato, tato e paladar) como alvo da avaliação. Após, são realizadas as instruções-perguntas (2.2) direcionadas aos processos ou níveis experiências afetivas (2.3) e cognitivas (2.5) específicas. São direcionadas, portanto, aos siste-mas afetivo e cognitivo que se desdobram em oito fragmentos ou níveis de experi-ência subjetiva. O total é de ao todo 8 instruções, e respeitam a hierarquia de pro-cessos afetivos e cognitivos sugeridas por Crilly et al. (2004), Khalid \& Helander (2004), Norman (1988, 2004), Wrigley, 2013) e demais autores abordados para a elaboração dos pressupostos, constructos e componentes do modelo.

Uma última pergunta (P.9) é proposta para a verificação da intenção de com-pra. Esta última variável de resposta é resultado da instrução-pergunta sobre a in-tenção de comprar ou não o produto (tabelas 4 e 5). É utilizada para a verificação e confirmação dos indicadores de cognitividade, afetividade e intencionalidade, por meio da análise das correlações existentes entre as 8 variáveis de resposta resul-tantes das instruçõesperguntas direcionadas aos processos ou sistemas afetivo e cognitivo que compõem a experiência de produto.

Tabela 4: Perguntas direcionadas aos processos sistemas afetivo e cognitivo específicos

\begin{tabular}{|c|c|c|}
\hline System & Nível de Experiência & Instrução-pergunta \\
\hline \multirow{4}{*}{ Afetivo } & Visceral (sensação) & $\begin{array}{l}\text { P.l: Que "sentimentos" você tem ao observar este } \\
\text { produto? }\end{array}$ \\
\hline & $\begin{array}{l}\text { Estética (percepção es- } \\
\text { tética) }\end{array}$ & $\begin{array}{l}\text { P.2: "Esteticamente", este produto para vocêé é de- } \\
\text { sagradável ou agradável? }\end{array}$ \\
\hline & $\begin{array}{l}\text { Simbólica* (associação } \\
\text { de imagens de signifi- } \\
\text { cado afetivo) }\end{array}$ & $\begin{array}{l}\text { P.5: O estilo deste produto tem para você um "sig- } \\
\text { nificado" desagradável ou agradável? }\end{array}$ \\
\hline & $\begin{array}{l}\text { Reflexiva* (reflexão afe- } \\
\text { tiva) }\end{array}$ & $\begin{array}{l}\text { P.6: Após pensar e "refletir" um pouco sobre o es- } \\
\text { tilo deste produto, você o considera desagradável } \\
\text { ou agradável? }\end{array}$ \\
\hline \multirow{4}{*}{ Cognitivo } & $\begin{array}{l}\text { Comportamental (usa- } \\
\text { bilidade) }\end{array}$ & $\begin{array}{l}\text { P.3: Qual sua "percepção" sobre a "facilidade de } \\
\text { uso" deste produto? }\end{array}$ \\
\hline & $\begin{array}{l}\text { Semântica (mensa- } \\
\text { gem, comunicaçăo) }\end{array}$ & $\begin{array}{l}\text { P.4: Você consegue "entender" as "funçöes" que } \\
\text { este produto propõe? }\end{array}$ \\
\hline & $\begin{array}{l}\text { Simbólica* (associação } \\
\text { de imagens de signifi- } \\
\text { cado cognitivo) }\end{array}$ & $\begin{array}{l}\text { P.7: A facilidade de uso deste produto tem para } \\
\text { você um "significado" difícil ou fácil? }\end{array}$ \\
\hline & $\begin{array}{l}\text { Reflexiva* (reflexão } \\
\text { cognitiva) }\end{array}$ & $\begin{array}{l}\text { P.8: Após pensar e "refletir" um pouco sobre a fun- } \\
\text { cionalidade deste produto, você o considera difi- } \\
\text { cil ou fácil? }\end{array}$ \\
\hline ençâa & $\begin{array}{l}\text { Viés de Intenção (cor } \\
\text { firmatório) }\end{array}$ & P.9: Você compraria este produto? \\
\hline
\end{tabular}

Fonte: Autor, 2019.

Todas as perguntas devem ser acompanhadas de uma escala que varia de 0 (difícil-desagradável) a 10 (fácil-agradável) conforme já apontado. A verificação de facilidade "cognitiva" é direcionada ao atributo funcional, e a verificação de agradabilidade "afetiva" é direcionada ao atributo hedônico. Essa é a forma de cruzar informações afetivas e cognitivas do produto e do consumidor em um único contexto de interação.

\subsubsection{Indicadores cognitivo, afetivo e de intencionalidade}

Como resultado das instruções-perguntas tem-se as respostas externas, ou requisitos de resposta do consumidor. A tabela 5 apresenta as medidas dos indicadores que resultam da experiência cognitiva e afetiva de produto (ver figura 5). As respostas são de baixa $(C R$ 's $<5)$ ou alta $(C R ' s>5)$ cognitividade, o que aponta para um produto difícil ou fácil de consumir na percepção do cliente. Pode ser de baixa (CR's<5) ou alta (CR's $>5$ ) afetividade, o que aponta para um produto desagradável ou agradável de consumir na percepção do cliente. E, através da apuração da mé-dia dos dois indicadores têm-se o indicador de intencionalidade, que pode ser de fraca $(C R$ 's $<5)$ ou forte (CR's $>5$ ) intencionalidade. $O$ viés de intencionalidade subje-tivo é validado por meio da instrução 9, que fornece a variável "intenção de compra" e serve de base e medida para análise da correlação com o indicador de intenciona-lidade.

Tabela 5: Requisitos de resposta do consumidor

\begin{tabular}{|c|c|c|c|c|}
\hline \multirow{3}{*}{$\begin{array}{l}\text { Requisitos de } \\
\text { resposta } \\
\text { do consumidor }\end{array}$} & $\begin{array}{l}\text { 1) Indicador de afetividade } \\
\text { (valores das variáveis de resposta } \\
\text { de P.1, P.2, P.5 \& P.6) }\end{array}$ & 0 à 10 & $<5<$ & Baixa/Alta \\
\hline & $\begin{array}{l}\text { 2) Indicador de cognitividade } \\
\text { (valores das variáveis de resposta } \\
\text { de P. } 3, \text { P. } 4, \text { P.7 e P.8) }\end{array}$ & 0 à 10 & $<5<$ & Baixa/Alta \\
\hline & $\begin{array}{l}\text { 3) Indicador de intencionalidade } \\
\text { (valores da média de } 1 \text { e } 2 \text { ) }\end{array}$ & 0 à 10 & $<5<$ & Fraca/Forte \\
\hline
\end{tabular}

Fonte: Autor, 2019.

Com as informações apresentadas as equipes de design de produto podem direcionar seus esforços ao tipo de atributo do produto que precisa ser melhorado. Se o produto deve ser mais "fácil e funcional" e, portanto, mais cognitivo, ou se o produto deve ser mais "agradável e hedônico" e, portanto, mais afetivo. Inclusive, saber com medidas quantitativas o viés subjetivo de intencionalidade e preferência do consumidor.

\section{CONCLUSÃO}

O objetivo deste artigo foi propor um modelo conceitual de avaliação e tradução da experiência cognitiva e afetiva de produto, por meio de uma abordagem multidisciplinar cognitivista. A abordagem resultou em um instrumento que propõe o cruzamento das informações oriundas do produto e do consumidor em um único contexto de interação e tem, como resultado, três indicadores para análise da experiência de produto, os indicadores de cognitividade, afetividade e intencionalidade.

O design cognitivo e afetivo de produto busca avançar no caminho de estrei-tar o espaço existente entre o produto e o consumidor. É a área de pesquisa que avança para entender a experiência subjetiva de produto. É a consciência dos efei-tos psicológicos, incluindo o grau em que todos os sentidos são estimulados, os significados e valores que são atribuídos aos produtos e os sentimentos e emoções que são provocados. Contudo, a experiência de produto fácil e agradável é subjeti-va e varia de consumidor para consumidor. Opiniões e respostas resultam de mu-danças internas nos sistemas afetivo e cognitivo. O modelo proposto considera os sistemas afetivo e cognitivo de 
maneira integrada, pois verifica-se que o afeto é de-terminante para a qualidade subjetiva da experiência de produto enquanto que a cognição é fundamental para a intenção e decisão final de escolha do consumidor. Avaliar e traduzir o viés subjetivo de intencionalidade e preferência é algo complexo e que demanda inovações constantes para seu entendimento e avaliação. O mode-lo demonstra potencial promissor em atender aos desafios em futuras aplicações.

Conclui-se que não é interessante direcionar esforços apenas para a avaliação do processo cognitivo ou afetivo do consumidor, ou também apenas a um tipo de atributo funcional ou hedônico do produto, sem levar em consideração as diferentes dimensões que compõem um produto e os diferentes aspectos psicológicos que integram a experiência subjetiva do consumidor, além do contexto em que essa experiência acontece. Para uma boa experiência de produto o produto deve ser, ao mesmo tempo, "cognitivo" e "fácil" e "afetivo" e "agradável" de se usar e consumir, e propomos que isto possa ser alcançado.

Como continuidade da pesquisa, os autores sugerem a aplicação do modelo de avaliação e tradução para avaliar e traduzir a experiência cognitiva e afetiva de produto. E apurar, em experimentos futuros, os indicadores de cognitividade, afetividade intencionalidade de produtos e sistemas. Nesse sentido, é sugerido que o modelo seja testado explorando todos os sentidos sensoriais (visão, tato, paladar, audição e olfato) explorando diferentes tipos de produtos digitais e tecnológicos em diferentes países e culturas.

\section{REFERÊNCIAS}

Aftab, M., \& Rusli, H. A. Designing Visceral, Behavioural and Reflective Products. Chinese J. of Mec Eng (English Edition), 30(5), 1058-1068, 2017

Artacho-Ramírez, M. A., Diego-Mas, J. A., \& Alcaide-Marzal, J. Influence of the mode of graphical representation on the perception of product aesthetic and emotional features: An exploratory study. IJIE, 38(11), 942-952, 2008.

Ashby, F. G., Isen, A. M., \& Turken, U. A neuropsychological theory of positive af-fect and its influence on cognition. Psychological Review (APA), Vol 106(3), 529-550, 1999.

Coates, D. Watches tell more than time: Product design, information and the quest for elegance. McGraw-Hill, 2003.

Crilly, N., Moultrie, J., \& Clarkson, P. J. Seeing things: Consumer response to the visual domain in product design. Design Studies, 25(6), 547-577, 2004.

Damasio, A. Some Notes on Brain, Imagination and Creativity. In: K. H. PFEN-NINGER, \& V. R. SHIBIK (Eds.), 2001.

Damasio, A., \& Adolphs, R. The interaction of affect and cognition: A neurobiological perspective. J. P. Forgas (Ed.), 2001.

Desmet, P. A multilayered model of product emotions. The Design Journal, 6, 4-13, 2003. Diego-Mas, J. A., \& Alcaide-Marzal, J. Single users' affective responses models for product form design. IJIE, 53, 102-114, 2016.

Dubet, F. Sociologie de l'expérience. Paris, Seuil, 1994

Ellsworth, P. C., \& Scherer, K. R. Appraisal processes in emotion (p. 572-595). Ox-ford University Press, 2003.

Engel, J. F., Blackwell, R. D., \& Miniard, P. W. Consumer Behavior (8o ed). Dryden Press, 1995.

Epstein, S. Integration of the Cognitive and Psychodynamic Unconscious. American Psychologist, 8(49), 709-724, 1994.

Ertmer, P. A., \& Newby, T. J. Behaviorism, cognitivism, constructivism: Comparing critical features from an instructional design perspective. 43-71, 2013.

Fukuda, S. Emotional engineering: Service development. Springer, 2011.

Gómez-Corona, C., Chollet, S., Escalona-Buendía, H. B., \& Valentin, D. Measuring the drinking experience of beer in real context situations. The impact of affects, senses, and cognition. F Quality and Pref, 60(Elsevier), 113-122, 2017. 
Han, S. H., \& Hong, S. W. A systematic approach for coupling user satisfaction with product design. Erg, 46((13/14)), 1441-1461, 2003.

Hirschman, E., \& Stern, B. The Roles of Emotion in Consumer Research. Ad Cons Res, 26, 4-11, 1999.

Ho, C. H., \& Lu, Y. N. Can pupil size be measured to assess design products? IJIE, 44, 436-441, 2014.

Jiao, R. J., Zhou, F., \& Chu, C. H. Decision theoretic modeling of affective and cogni-tive needs for product experience engineering: Key issues and a conceptual framework. $J$ of Int Man, 28(7), 1755-1767, 2017.

Jordan, P. W. Human factors for pleasure in product use. App Erg, 29(1), 25-33, 1998.

Jordan, P. W. Pleasure with products: Human factors for body, mind and soul, 1999.

Jordan, P. W. Designing Pleasurable Products. Taylor and Francis, 2000.

Kahneman, D. Thinking fast and slow. Farrar, Straus and Giroux, 2011.

Kahneman, D., \& Tversky, A. Prospect theory: An analysis of decisions under risk. 47, 313-327, 1979.

Karim, A. A., Lützenkirchen, B., Khedr, E., \& Khalil, R. Why Is 10 Past 10 the De-fault Setting for Clocks and Watches in Advertisements? A Psychological Experiment. Fron-tiers in Psychology, 8, 2017.

Khalid, H. M., \& Helander, M. G. Customer Emotional Needs in Product Design. Conc Eng, 14(3), 197-206, 2006.

Khalid, H. M. Embracing diversity in user needs for affective design. App Erg, 37(4), 409418, 2006.

Khalid, H. M., \& Helander, M. G. A framework for affective customer needs in prod-uct design. T Issues in Erg Sc, 5(1), 27-42, 2004.

Kumar, M., \& Garg, N. (2010). Aesthetic principles and cognitive emotion appraisals: How much of the beauty lies in the eye of the beholder? Journal of Consumer Psychology, $20(4), 485-494$.

Li, X., Zhao, W., Zheng, Y., Wang, R., \& Wang, C. Innovative Product Design Based on Comprehensive Customer Requirements of Different Cognitive Levels. The Scientific World Journal, 2014.

Lu, W., \& Petiot, J. F. Affective design of products using an audio-based protocol: Application to eyeglass frame. IJIE, 44, 383-394, 2014.
Maturana, H. R., \& Varela, F. J. The Tree of Knowledge: The Biological Roots of Hu-man Understanding. Shambala/New Science Library, 1987.

Neisser, U. (2009). Cognitive Psychology, New York: Appleton-Century-Crofts, 2009.

Noble, C. H., \& Kumar, M. Using product design strategically to create deeper con-sumer connections. Business Horizons, 51(5), 441-450, 2008.

Norman, D. The Design of Everyday Things. New York: Basic Books, 1988.

Norman, D. Emotional Design: Why We Love (or Hate) Everyday Things. Basic Books, 2004.

Orth, D., \& Thurgood, C. Designing Objects with Meaningful Associations. 12(2), 14, 2018. Parrott, G., \& Sabini, J. On the "emotional" qualities of certain types of cognition: A reply to arguments for the independence of cognition and affect. Cognitive Therapy and Res, 13(1), 49-65, 1989.

Picard, R. W., Papert, S., Bender, W., Blumberg, B., Breazeal, C., \& Cavallo, D. Af-fective learning-A manifesto. BT Technology Journal, 253-269, 2004.

Pritchard, A. Cognitive, constructivist learning (3rd ed.). Routledge, 2014.

Rindova, V. P., \& Petkova, A. P. When Is a New Thing a Good Thing? Technological Change, Product Form Design, and Perceptions of Value for Product Innovations. Organization Science, 18(2), 217-232, 2007.

ROZENFELD, H. et al. Gestão de desenvolvimento de produtos: Uma referência para a melhoria do processo. Saraiva, 2006.

Schifferstein, H. N., \& Hekker, P. Product experience. Elsevier, 2011.

Seva, R. R., Gosiaco, K. G. T., Santos, Ma. C. E. D., \& Pangilinan, D. M. L. Product design enhancement using apparent usability and affective quality. App Erg, 42(3), 511-517, 2011 Seva, R. R., \& Helander, M. G. The influence of cellular phone attributes on users' affective experiences: A cultural comparison. IJIE, 39(2), 341-346, 2009.

Slovic, P., Finucane, M., Peters, E., \& MacGregor, D. G. The affect heuristic. In Intuitive Judgment: Heuristics and Biases. (p. 397-420). Cambridge University Press, 2002.

Storbeck, J., \& Clore, G. L. On the interdependence of cognition and emotion. Cognition Emotion, 21(6), 1212-1237, 2007.

Tavares, D. R. A busca de solução para o 'problema difícil' da consciência: Uma revisão das perspectivas de Chalmers, Dennett e Damásio. Ciências e Cognição, Vol 23(1), 138-157, 2018. 
Turner, J. A., \& Laird, A. R. The Cognitive Paradigm Ontology: Design and Applica-tion. Neuroinformatics, 10(1), 57-66, 2012.

Vygotsky, L. Thought and Language. MIT Press, 1962.

Wrigley, C. Design dialogue: The visceral hedonic rhetoric framework. Design Issues, 29(2), 82-95, 2013.

Wrigley, C. J. Visceral Hedonic Rhetoric. 2011, Thesis PhD.

Zajonc, R. B. Feeling and thinking: Preferences need no inferences. American Psychologist, 35, 151-175, 1980.

Zhou, F., Ji, Y., \& Jiao, R. J. Affective and cognitive design for mass personalization: Status and prospect. J of Int Man, 24(5), 1047-1069, 2013. 